\title{
CAPS - FLORIANÓPOLIS: UMA EXPERIÊNCIA DE GRUPO COM CLIENTES PSICÓTICOS FORA DOS MUROS DO MANICÔMIO, DURANTE DEZ ANOS ${ }^{1}$
}

\author{
"CAPS" FROM FLORIANÓPOLIS: A GROUP EXPERIENCE WITH \\ PSYCOTIC CLIENTS OUTSIDE THE MENTAL HOSPITAL'S WALLS, \\ DURING TEN YEARS \\ "CAPS" - UNA EXPERIENCIA DE GRUPO CON PACIENTES \\ PSICÓTICOS FUERA DE LOS MUROS DEL MANICOMIO, \\ DURANTE DIEZAÑOS
}

Dorotéa Loes Ribas ${ }^{2}$

Miriam Süsskind Borenstein ${ }^{3}$

\begin{abstract}
RESUMO: Trata-se de um relato de experiência realizado junto a clientes psicóticos crônicos desinstitucionalizados, que estiveram em acompanhamento por uma enfermeira num CAPS/NAPS de Florianópolis, durante dez anos, ou seja de 1989 a 1999. Ao final desse periodo, pode-se visualizar que clientes psicóticos crônicos, quando em um acompanhamento sistemático com vínculo com o grupo terapêutico conseguem manter uma vida relativamente saudável, alcançando objetivos, superando crises e mantendo-se fora dos muros do manicômio.
\end{abstract}

PALAVRAS-CHAVE: clientes psicóticos, enfermagem, assistência psiquiátrica, CAPS

\section{INTRODUZINDO A PROBLEMÁTICA DO ESTUDO}

Durante mais de um século (1852-1990) no Brasil, o atendimento ao doente mental esteve praticamente limitado a internação em grandes hospitais psiquiátricos estatais. Além destes hospitais, posteriormente foram criadas clinicas psiquiátricas privadas. Embora menores, não fugiam da proposta inicial de retirar o doente de seu meio social, para tratá-lo. Com o passar do tempo, observou-se que estes recursos, ao contrário de tratar, muitas vezes cronificavam os doentes. Em algumas situações os hospitais se caracterizavam como verdadeiros "depósitos de doentes mentais" e o tratamento dispensado se caracterizava por ser desumano e cruel.

A partir do final da década de 70 , os trabalhadores de saúde mental começaram a desencadear um movimento de mudança de tal realidade, para oferecer um tratamento mais humanizado e efetivo, resgatando a cidadania do doente mental. Passam então, a discutir em todos os fóruns (Congressos Brasileiros de Psiquiatria, Conferências Nacionais de Saúde Mental, entre outros) a necessidade de reverter esta situação. Destas discussões consubstanciou-se a proposta da reforma psiquiátrica brasileira, onde deveriam ser considerados alguns pontos fundamentais como: reverter a tendência hospitalocêntrica através da priorização de implantação de um sistema extra-hospitalar e multiprofissional de assistência; proibir a construção de novos hospitais psiquiátricos e a sua substituição por leitos psiquiátricos em hospitais gerais; o

\footnotetext{
1 Prêmio Jane Fonseca Proença, $1^{\circ}$ lugar, $51^{\circ} \mathrm{CBEn}$.

${ }^{2}$ Enfa. do CAPS - Florianópolis/SC - Especialista em Adm. Hospitalar.

${ }^{3}$ Profa. Adjunto do Departamento de Enfermagem da UFSC.
} 
credenciamento de novos leitos em hospitais convencionais, e promoção da saúde mental integrando-a à outros programas de saúde, movimentos sociais e instituições (Fraga, 1994).

Um fator que contribuiu significativamente foi a criação da Portaria No. 224, de 29 de janeiro de 1992, do Ministério da Saúde a qual prescreveu a criação de Núcleos/ Centros de Atendimento de Atenção Psicossocial (NAPS/CAPS). Foram instituídos como unidades de saúde locais/ regionalizadas que deveriam: a) conter uma população geograficamente definidas pelo nível local; b) oferecer atendimentos de cuidados intermediários entre o regime ambulatorial e a internação hospitalar; c) ser a porta de entrada da rede de serviços para ações relativas à saúde mental, considerando sua caracteristica de unidade de saúde local e regionalizada; d) atender a pacientes referenciados por outros serviços de saúde, dos serviços de urgência psiquiátrica ou ainda egressos de internação hospitalar; e) funcionar em horário comercial, e estar integrados a uma rede descentralizada e hierarquizada de cuidados em saúde mental, assistidos por uma equipe multiprofissional, constituida prioritariamente por: médico psiquiatra, psicóloga, enfermeira e assistente social (BRASIL, 1992). Os NAPS/CAPS, passaram ainda que de forma indelével, à modificar a assistência até então oferecida aos doentes psiquiátricos institucionalizados.

Em Santa Catarina, antes mesmo da criação do CAPS/NAPS pelo governo federal, ocorreu uma mudança de mentalidade em termos técnicos e políticos. No início da década de 70 , o governo estadual abandonou a idéia de construir novos hospicios, inclusive deixando de inaugurar o Hospital Psiquiátrico de Chapecó. Resolveu ainda levar adiante o programa de diminuição gradativa de leitos no macro Hospital Colônia Sant'Ana, dotando este hospital de um número maior de recursos humanos e materiais.

Depois de mais de uma década da Reforma Psiquiátrica introduzida em Santa Catarina, a área de psiquiatria passou a contar com uma série de recursos terapêuticos como: uma rede de NAPS/CAPS atuando em todo o Estado, o Instituto de Psiquiatria (IPQ), (antigo Hospital Colônia Sant'Ana agora reformulado), outros hospitais psiquiátricos da rede particular (Instituto São José - SJ, Rio Maina - Criciúma, entre outros) e ainda, passou a internar pacientes psiquiátricos em leitos de hospitais gerais. Embora longe do ainda considerado ideal para tratamento de doentes psiquiátricos, alguns trabalhos têm merecido destaque por sua ação junto aos doentes, um deles é o que vem se desenvolvendo no CAPS da capital. Pois os CAP/ NAPS concebidos como estruturas abertas ao atendimento de emergências, como um espaço de convivência, como um local de referência para o usuário em crise, como uma instituição ativadora dos recursos comunitários, da integraçăo paciente, familia e comunidade, tem possibilitado a inúmeros clientes psiquiátricos que o buscam, vivenciar o seu cotidiano, atuando como um verdadeiro recurso terapêutico, minimizando crises, fortalecendo as relações e estimulando para as questões saudáveis. Este estudo tem como objetivo principal relatar a experiência de dez anos de uma enfermeira junto a um grupo de clientes psicóticos vinculados ao CAPS/NAPS de Florianópolis.

\section{APRESENTANDO O CAPS}

\section{O CAPS}

O CAPS de Florianópolis foi criado em 1989 para realizar a assistência secundária a clientes adultos que apresentassem transtornos psiquicos e outros a elas vinculados. Tratavase do primeiro recurso não manicomial da rede pública do Estado. Atualmente é referência para vinte um municípios da Grande Florianópolis. O CAPS está inserido na Policlínica de Referência Regional III, e localiza-se no centro de Florianópolis, na rua Esteves Júnior, no. 390 - andar térreo, bloco G.

O CAPS dispõe atualmente de sete salas, sendo uma sala de espera com balcăo, onde ocorre 
a recepção do cliente pelo agente administrativo, uma para a enfermagem, uma para a terapia ocupacional, uma para administração, onde estão os prontuários e todos os materiais administrativos (impressos), uma para lanche dos funcionários, duas salas para terapia de grupo, uma sala onde está sendo implantado uma oficina terapêutica, três consultórios para atendimento psicológico, médico e do serviço social, e finalmente dois banheiros, sendo um para funcionários, e outro para os clientes. A equipe técnica do CAPS é composta por três psiquiatras, um médico clínico, três psicólogas, três enfermeiras, duas assistentes sociais, dois agentes administrativos e duas terapeutas ocupacionais .

\section{A DINÂMICA GERAL DO CAPS ( ATIVIDADES, TERAPIAS UTILIZADAS, PROFISSIONAIS)}

O CAPS desenvolve basicamente três programas: Programa para Ansiosos, Programa para os Dependentes Químicos e o Programa para Psicóticos.

O Programa para Ansiosos atende geralmente a pacientes com transtornos neuróticos. As modalidades de atendimento variam e se caracterizam por triagem semanal, psicoterapia individual, de grupo, de casal e de familia. $\mathrm{O}$ atendimento é realizado por três psicólogas e quando necessário os pacientes são encaminhados para os médicos psiquiatras que muitas vezes recebem a indicação para uso de medicação.

O Programa para os Dependentes Quimicos atende adolescentes e adultos que fazem uso de álcool e outras drogas. O objetivo é auxiliar o individuo e a familia que buscam o tratamento para a desintoxicação, para a manutenção da abstinência e para a busca de uma melhor qualidade de vida. Procura facilitar e favorecer o processo da abstinência não retirando o paciente do seu meio e buscando integrá-lo ao mesmo. Procura tratar o paciente no sistema integrado com os demais pacientes, reduzindo os custos com o processo de tratamento ambulatorial. As modalidades de atendimento se dão a nivel individual e grupal.

O Programa para Psicóticos atende os pacientes egressos do I.P.Q. . O objetivo é manter o cliente em tratamento extra-hospitalar, vinculado à familia com perspectivas de retomada das atividades de vida diária, interativas e sociais. As modalidades de atendimento deste programa se constituem em triagem diária, atendimento individual e grupal que são realizados pela enfermeira, assistente social, médico psiquiatra e clínico, terapeuta ocupacional.

Neste estudo, como dito anteriormente, pretende-se abordar mais especificamente os clientes psicóticos, que estão vinculados ao grupo de auto - ajuda, coordenado por uma enfermeira.

\section{RELATANDO A EXPERIÊNCIA NO GRUPO DE AUTO-AJUDA}

\section{PROGRAMA PARA PSICÓTICOS - O GRUPO DE AUTO-AJUDA}

Os grupos de auto-ajuda segundo Zimerman e Osório (1977), se caracterizam por aqueles de formação espontânea entre pessoas que se identificam por algumas caracteristicas semelhantes entre si, e se unem quando se dão conta que têm condições de se ajudarem reciprocamente. Outras vezies, estes grupos se formam a partir de um estimulo integrador de algum profissional que coordena o grupo, até que o mesmo tenha chegado o momento certo de caminhar sozinho, então o profissional se afasta definitiva ou transitoriamente, mantendo-se disponivel para o grupo que ele ajudou a formar. Os grupos de auto-ajuda săo, portanto, compostos por pessoas portadoras de uma mesma categoria de problemas e de necessidades, que, de uma forma geral, podem ser enquadradas em seis tipos: dos adictos, das pessoas que possuem necessidades de cuidados primários de saúde, das que necessitam de reabilitação, 
dos que necessitam de apoio para sobrevivência social, dos que possuem problemas conjugais e sexuais, e dos que necessitam de suporte, como pacientes crônicos, físicos ou psíquicos, pacientes terminais e outros.

A partir de uma maior compreensão da conceituação de grupos, quando pensamos em trabalhar com clientes psicóticos no CAPS, em Florianópolis, optamos pelo grupo de autoajuda, que seria mais adequado ao propósito que tínhamos em mente.

\section{A DINÂMICA}

A seleção dos clientes para participar do grupo de auto-ajuda atendeu a alguns critérios como: serem doentes mentais crônicos adultos, egressos de hospitais psiquiátricos com várias internaçöes e com interesse em participar de atividade grupal. Os encontros passaram a ser realizados semanalmente, às sextas feiras, das dez as onze horas, ou seja, com uma hora de duração. Nestas reuniőes năo participaram familiares.

Em geral se inicia a reuniăo fazendo uma retrospectiva do que foi a semana para cada um dos membros integrantes, em que abordam o seu cotidiano, as relações e os problemas enfrentados. Num segundo momento, conforme o interesse do grupo, são trazidos assuntos diversos, normalmente os assuntos que mais aparecem, estăo relacionados com a doença, dúvidas em relação à medicaçăo, efeitos colaterais, problemas relacionados com a sexualidade, como a ereção e a amenorréia. Além desses assuntos os clientes costumam questionar acerca do uso da medicação, dos riscos de virem apresentar novas crises e de outros assuntos relacionados.

A partir dos encontros realizados nestes dez anos, alguns assuntos mereceram uma especial atenção por parte de todos os integrantes do grupo, exatamente porque estão diretamente relacionados com os problemas ocasionados pela doença. Apresentamos a seguir alguns dos problemas relatados. No entanto a fim de não expor estes clientes, procurando proteger as suas individualidades e respeitando os principios éticos, optamos por denominá-los por nomes de flores, dessa forma conseguiremos abordar as principais situações de seus cotidianos, sem expor as suas identidades.

Dos assuntos discutidos, podemos referir que um dos temas que tem sido bastante evidenciado está relacionado com o uso de medicação.

\section{USO DE MEDICAÇÃO}

As dúvidas dos pacientes geralmente estão relacionadas com os efeitos colaterais que a medicação psiquiátrica causa, com o tempo que deverão tomar esta medicação e, principalmente, se podem ingerir álcool associado ao uso da medicação. Solicitam informações, para saber como lidar com estas questőes, mas principalmente para evitar que possam ocorrer problemas ainda maiores.

As mulheres que participam do grupo trazem muitas dúvidas a respeito da amenorréia, $e$ também em relação a gravidez. Rosa, uma das participantes do grupo, quando começou a tomar o Haldol, um neuroléptico que costuma causar amenorréia, logo procurou compartilhar com os demais membros, suas dúvidas, referindo:

(...) Eu gostaria de saber porque minha menstruação atrasou? Afinal eu menstruava todo mês certinho e agora faz quase dois meses que não veio. Isso é normal? Violeta que possui um maior conhecimento sobre o assunto, já que utiliza medicação neuroléptica há longo tempo, procurou esclarecer e acalmar Rosa, explicando da seguinte forma:

(...) Rosa isto é normal, e é porque tomamos esses remédios. Quando iniciei meu tratamento aconteceu a mesma coisa. Eu me cuidava e meu marido usava camisinha até que a minha menstruação voltou ao normal. 
Nos homens a dúvida que surge é em relação à impotência que os neurolépticos costumam causar, decorrentes do seu efeito colateral. Lírio, Narciso e Crisântemo, outros três participantes, nada referem sobre este assunto, entretanto Cravo e Antúrio relatam que perceberam a impotência. Cravo se manifestou da seguinte maneira:

(...) eu ontem fui me masturbar e não consegui ter ereção. Isto é normal? Fiquei muito preocupado. Já tomo Haldol há anos e nunca me aconteceu isto. Será que isto aconteceu porque o médico aumentou a dose da medicação?

Antúrio percebeu o problema quando separou-se de sua esposa. Depois de muito tempo arrumou uma namorada, e quis ficar mais intimo dela, e assim ele se expressou:

(...) Dorotéa, ontem eu sai com minha namorada depois tivemos relação sexual e eu não consegui chegar no climax. Tentei, tentei mas não deu. Ficamos em silêncio... .

Logo depois expliquei para ela, que só podia ser por causa dos remédios que tomo. Ai eu disse: deixa que eu vou perguntar no próximo encontro no CAPS.

Outra dúvida que surge a respeito é quanto ao uso da bebida alcoólica em associação com o da medicação. É sabido que o álcool interage com os medicamentos, podendo potencializar certos efeitos como a agitação, a sonolência e a sedação.

Antúrio preocupava-se muito com esta questão, pois no início suas recaídas se davam geralmente no período de carnaval, quando misturava a bebida alcóolica com o uso de medicamentos. Hoje porém após várias reinternaçőes, descobriu que mais importante é manter sua saúde mental, e por isso deixou de beber já há quatro anos, e nunca mais apresentou problemas desse tipo.

\section{ATIVIDADE LABORAL}

A atividade laboral faz parte integrante da vida do homem, especialmente no mundo atual, em que o trabalho tem um valor inestimável e o homem é reconhecido pelo trabalho que produz e pela posiçăo social que ocupa na sociedade. Assim como o homem considerado "sadio" necessita ter uma ocupação, o doente psiquiátrico também necessita para sentir-se ativo, participante, útil para a sociedade e, principalmente para evitar que estando ocioso, provoque a cronicidade da doença. Observamos que dos oito integrantes do grupo, seis estão aposentados por causa da doença. Uma das clientes não está aposentada porque nunca contribuiu para a Previdência, e apenas um dos clientes, se mantém no mercado de trabalho. Quando esse assunto emerge na reunião, todos são unânimes e concordam que na necessidade de uma atividade laboral diária. Cada um dos membros do grupo expõe aos demais, o que costuma realizar no seu cotidiano. Rosa que é muito ativa, gosta de preencher seu tempo de forma integral. Apesar de ter sido orientada para realizar atividades moderadamente, a fim de evitar o stress e a possibilidade de uma nova crise, revela:

(...) Dorotéa quando eu estou boa, fora da crise. Eu cuido da locadora que montei junto com meu filho. Na Páscoa faço chocolate porque sempre é um lucro que tenho. No verão faço sorvete e os guris da rua vem lá em casa para comprar ou ajudar a vender.

Cravo entretanto, já apresenta algumas limitaçőes devido a cronicidade da doença e por esse motivo consegue realizar somente atividades num processo muito mais lento, conforme seu próprio relato:

(...) Olha como eu tenho duas irmãs que trabalham o dia inteiro fora, então eu cuido do meu pai. Ele já tem oitenta e cinco anos, não enxerga bem. Cuido dele e assim em troca, minhas irmãs dão roupa para mim. Sabe ganho somente um salário mínimo e é difícil adquirir muitas coisas. Eu que vou na padaria, farmácia comprar quando falta alguma coisa lá em casa.

Antúrio é o único cliente que continua em atividade no serviço público estadual. Por causa da crise econômica e do seu salário muito reduzido, ele conseguiu encontrar uma forma 
de aumentar o seu rendimento. Comprou todo material para jardinagem e atualmente à fim de engordar o seu salário, ele procura terrenos e jardins para limpar, ele costuma colocar:

(...) Dorotéa andei muito afastado do meu serviço por causa da doença. Mas depois dos atestados que o médico deu trabalho só quatro horas. A tarde posso fazer serviço de jardinagem. Além de ganhar um dinheiro extra que ajuda no meu tratamento. Porque o meu serviço é burocrático, ás vezes fico muito pensativo. (Antúrio) .

Outro assunto que permeia as reuniőes do grupo, se refere ao tema a seguir:

\section{A FAMILIA}

Hoje mais do que nunca, sabemos que a familia desempenha um importante papel no tratamento do doente mental, assim como no tratamento de qualquer outra enfermidade crônica grave. O tratamento do doente psiquiátrico tem um melhor prognóstico quando a família se envolve efetivamente no seu tratamento.

Rosa é uma cliente que durante suas crises costuma abordar muitas questões sobre sua familia. É divorciada e vive com seu filho de vinte anos. Seu pai, com quem mantinha excelente relação, já é falecido. Sua mãe mora em Curitiba, acompanha sua filha à distância, e quando ela esta não está bem, costuma sugerir a internação. Nas últimas vezes que esteve em crise não falou mais com sua mãe. E referiu o seguinte em relação a familia:

(...) Sabe a minha familia é muito safada comigo. Uma vez eu estava internada e fizeram eu assinar papéis por isso não tive direito a receber nada. Mas quando a crise passa eu esqueço tudo o que passei. Hoje estou melhor tenho o meu canto. Moro com meu filho. Quando estou na crise tomo os remédios e sinto muito sono. Fecho minha casa e vou dormir. Assim fico calma e ninguém me interna.

Cravo refere ser feliz, tem uma familia que se envolve com ele e costuma participar do seu tratamento. Mora com seu pai e duas irmãs. Elas trabalham em periodo integral e Cravo permanece com o pai. Quando adoece todos participam, ajudando. Da mesma forma que Cravo, Crisântemo, que é viúvo, tem os filhos e um genro que participam do seu tratamento. Crisântemo passa periodos na casa de cada filho. Um desses filhos, costuma levá-lo ao médico regularmente, para pegar a receita. Segundo as falas de ambos, a familia costuma ser bem envolvida, como podemos verificar a seguir:

(...) Dorotéa, hoje meu irmão veio junto. Eu estou com um leve descontrole. Meu irmão achou que eu não podia vir sozinho. Mas se o médico aumentar a dose já fico melhor(Cravo)

(...) Sabe Dorotéa, hoje meu genro teve que vir junto. Fico com medo de sair sozinho durante a crise porque fico desorientado. Não sei onde estou e nem onde vou (Crisântemo).

\section{ADERENNCIAAO TRATAMENTO}

O tratamento do paciente psicótico para ser eficaz, se faz necessário o uso contínuo de medicação, associada com outras abordagens psicossociais. "Na grande maioria dos casos, as pessoas com distúrbios psiquiátricos, com o passar do tempo passam a apresentar seqüelas, principalmente relacionadas com a afetividade e vontade. Apresentam apatia, perda da motivaçăo, interesse, embotamento afetivo e dificuldade para tomar iniciativas no seu dia-a-dia. Compreender que falta de iniciativa e apatia são sintomas da doença e não "preguiça, desleixo ou vagabundagem é fundamental. $O$ doente mental tem limitações e, por isso, não adianta exigir dele algo que não consegue realizar. É fácil perceber as limitações de alguém numa cadeira de rodas, mas é difícil enxergar uma deficiência que só se manifesta psiquicamente"(Louzã, 1995).

A medicação e outras abordagens utilizadas visam auxiliar o paciente à sua reintegração global. Por esses motivos é necessário que a equipe multiprofissional se instrumentalize e consiga a partir das condiçőes do doente utilizar-se de diferentes abordagens, planejando e 
implementando um tratamento adequado, visando a adaptação psicossocial.

Durante o tempo de realização do grupo, dois clientes abandonaram o tratamento e dois foram admitidos.

Rosa comenta que reconhece a importancia do tratamento no CAPS, e sente-se agradecida pelo atendimento recebido, enquanto que Cravo refere, também gostar muito do pessoal e reconhece a importância do uso da medicaçăo, conforme o relato dos dois:

(...) se não fosse o CAPS não sei o que seria de mim. Aqui vocês entendem a minha doença e sei que posso vir aqui quando estou em crise. O grupo ajudou-me a não internar mais. Espero não precisar mais me internar. Já entendi que nós todos aqui temos os mesmos problemas e assim fica mais fácil a gente se ajudar. Só no inverno venho pouco porque tomo remédio para dormir e de manhã quero ficar na cama (Rosa).

(...) Sabe Dorotéa, eu para não esquecer como tomar os remédios tenho escrito num papel. Esse papel fica comigo e quando venho aqui trago também. Quando estou em crise dou para minhas irmås lerem comigo. Quando comecei a me tratar tomava menos remédio que hoje. Mas o importante é que me trato. Nós odos aqui temos o mesmo problema aí fica mais fácil de a gente se ajudar.

Também o pessoal do CAPS sempre me recebe bem. Aqui näo tem preconceito, mas lá fora... (Cravo).

No tema a seguir, observamos como cada cliente enfrenta as situações que vivencia no seu cotidiano e como estas, refletem no seu tratamento

\section{VIVENCIANDO EXPERIENNCIAS EMOCIONAIS NO SEU DIA-A-DIA}

Quanto à expressão das emoções, o doente mental às vezes manifesta o que se denomina "afeto inadequado". Isto significa demonstrar uma emoção que não tem relação com o que a pessoa pensa ou diz ou refere. Outras vezes podem apresentar um afeto embotado. Isto representa uma severa reduçăo da capacidade de expressar emoçōes. Não devemos marginalizálo, nem distanciá-lo da realidade. Devemos realizar uma ponte com o mundo para que situaçōes, que às vezes nos parecem ser fáceis de contornar, para eles também o sejam. A equipe deve preparar o paciente para conviver com as inevitáveis crises que ocorrerão na sua vida pessoal.

Este tema surge várias vezes no grupo, quando um dos integrantes está sob pressão e necessita enfrentar uma situação emocional muito forte. Cada qual enfrenta da sua maneira, utilizando mecanismos para abrandar a dor que vivencia.

Rosa costuma colocar muito suas emoções, principalmente quando envolve-se em relacionamentos amorosos que não se concretizam. Ela sofre muito. Chora no grupo e este demonstra um grande respeito e solidariedade. Segundo ela, seus parceiros são pessoas que costumam explorá-la financeiramente, pois ela possui uma vida econômica estável. Depois que divorciou-se do seu marido, passou a viver com outro companheiro durante sete anos. Depois disso sente necessidade de um outro companheiro para compartilhar suas vivências do dia-adia, conforme relato dela própria:

(...) Sabe Dorotéa, eu queria arrumar uma pessoa que me entendesse. Que aceitasse a minha doença,prque o meu filho já está grande e daqui a pouco ele arruma uma namorada e vai me deixar. Mas eu acho que hoje os homens só querem aproveitar. Sabe aquele namorado que eu tinha. Ele bebia e queria que eu ficasse dando dinheiro. Se a gente saía com o carro dele eu tinha que encher o tanque. Acho um desaforo afinal sou doente e ganho só um salário mínimo e mais o dinheiro da locadora.

Crisântemo vivenciou uma experiência a qual não conseguiu compartilhar no grupo. Ficou muito ansioso, choroso. Veio com familiares acompanhado ao CAPS.

(...) Dorotéa, minha esposa faleceu. Entendo que ela estava sofrendo, mas afinal ela era minha companheira durante todos esses anos. Sempre soube entender sobre a minha doença. 
Vim com minha filha porque parece que vai me dar uma crise. Eu tenho medo de ficar desorientado e não saber onde estou. Mas agora eu sei que ela está em paz.

O grupo escutou atentamente o que Crisântemo falou, logo após alguns membros procuraram confortar o companheiro, falando palavras de consolo e solidariedade. Todos os membros do grupo já vinham há longo tempo acompanhando a situação derisântemo, pois sua esposa encontrava-se hospitalizada e sofria seriamente devido as complicações crônicas da diabete mellitus. A morte ainda é considerada um tabu na sociedade ocidental e se caracteriza como uma grande perda, para qualquer tipo de pessoa, considerada saudável ou não.

\section{AS RECAIDAS}

Esse é um dos temas que freqüentemente tem sido objeto de discussão, pois está particularmente presente na vida dos pacientes psicóticos. Esta preocupação é eminente porque mesmo tomando a medicação regularmente a tendência de uma nova crise, poderá ocorrer. Por outro lado, a maior preocupação é se houver a necessidade de uma reinternação. Esta é considerada um fracasso. A reinternação para muitos se faz necessário porque em casa, não conseguem controlar seus delírios e alucinaçőes, assim como outros sintomas, como: insônia, inapetência, angústia, falta de ânimo, entre outros. Em algumas ocasiőes a situação fica ainda mais complicada, quando há riscos de vida para si e para os outros.

Segundo Louzã (1995) os sinais indicativos de inicio de recaida săo: tensão, irritabilidade, insônia, nervosismo, dificuldade de concentraçăo, isolamento, sensação de estranheza e agitação.

No grupo, observamos que pela convivência de longo tempo e por apresentarem a mesma patologia conseguem perceber quando algum dos membros está em surto. Na sala de recepção do CAPS, enquanto aguardam pela reunião, os membros do grupo já comentam entre si, quando percebem que um dos membros não está bem. Este é um amadurecimento grupal e tem contribuido no auxilio dos membros como um todo, diminuindo o sofrimento psíquico daquele que não está bem, principalmente pela coesão e apoio. Cada um dos membros tem uma forma muito particular de expressar o seu mal estar, conforme seus próprios relatos.

Cravo é um cliente que percebemos que quando está em crise, vem ao balcão com seu irmão e apresenta-se com manifestações de choro e falando muito alto. Costuma inclusive referir o seguinte:

(...) Dorotéa, hoje estou um pouco descontrolado. Andei cantando, chorei porque lembrei da minha mãe. Também meu sono estádifícil de chegar. Acho que o médico tem que aumentar a minha dose. Meu irmão disse para eu ficar mais em casa, porque quando estou na crise quero caminhar e às vezes nem sei onde estou, fico perdido andando de um lado pro outro, sem saber para onde ir .

Rosa já é uma cliente que pelo olhar percebe-se que está em crise. Às vezes apresentase logorréica, ansiosa para relatar o que esta ocorrendo:

(...) Dorotéa, tenho de falar bastante. Andei me aborrecendo. Chorei porque acho que tem pessoas que só sabem magoar. Ai se eu não vier, é porque estou lá. Sabe né?

Crisântemo entretanto quando está em crise, fica muito ansioso, perdido, desorientado o no tempo e no espaço, não consegue aguardar pelo atendimento médico e de enfermagem, manifestando-se da seguinte forma:

(...) Dorotéa estou perdendo o sono. Isso não é bom sinal. Tenho de começar a andar em rumo. Uma vez parei até na cadeia e só fui saber onde estava no terceiro dia preso. Também fico mais emocionado e quero ficar só rezando. Deus vais me salvar... .

Estas são algumas das inúmeras experiências vivenciadas pelo grupo de clientes psicóticos nestes dez anos. Observamos que com a realizaçăo das reuniőes semanais, em que os integrantes do grupo expressam seus sentimentos, suas ansiedades e realizaçőes, 
tem propiciado para que as internações se tornem esporádicas e com duração muito mais reduzida, causando menores prejuizos. Embora a doença cause restriçőes, os clientes têm permanecido por um tempo maior fora dos hospitais, ou seja, vivendo de forma mais saudável. (dentro do que se considera como "normalidade").

\section{CONCLUINDO PORÉM NÃO ENCERRANDO}

Após dez anos de uma longa convivência com um grupo de clientes psicóticos, podemos sem sombra de dúvidas referir que trata-se de algo de valor, pois se a principio o grupo serviu como desafio para a coordenadora, a proposta conseguiu chegar muito mais longe, avançou, ou seja extrapolou as expectativas, pois houve enorme crescimento de todas as partes envolvidas mas, especialmente, para os clientes que dele fazem parte. O grupo que inicialmente buscava se reunir para dividir algumas de suas angústias, tristezas, conseguiu uma coesão e passou a ter um espírito de grupo, onde cada um dos seus membros passou a contar com seus pares năo só para dividir tristezas e angústias mas, também, para compartilhar das suas conquistas e dos seus desafios.

É interessante observar a franqueza com que cada um se coloca, inclusive nas coisas mais intimas como: relacionadas à familia, às relaçŏes amorosas, à questăo sexual e, principalmente, em relaçăo as recaidas, em que o assunto afeta à todos.

Observamos que este novo serviço de saúde recém instituido pelo Ministério da Saúde, - CAPS, conseguiu possibilitar uma nova forma de tratar que năo o antigo modelo hospitalocêntrico. Este recurso está muito mais relacionado com uma proposta terapêutica, em que a terapeuta, no caso a enfermeira, mantém com os clientes uma relaçăo de igualdade, mais democrática, mais horizontal, apesar de longe do ideal de tratamento para doentes psiquiátricos. Este tipo de abordagem dentro de uma instituiçăo aberta permite que os clientes cheguem mais perto dos terapeutas e consigam uma interaçăo maior, resultando numa melhora do quadro psiquiátrico e social.

Visamos demonstrar que, no grupo em estudo, atingimos o objetivo primordial, que éo da não internaçăo. Também podemos observar que o grupo apresenta coesăo, confiança, estímulo, talvez pelo fato de possuirem quase todos a mesma problemática. Outro dado relevante é que o grupo ajuda a minimizar a cronicidade da doença, apesar das seqüelas que a doença mental provoca.

Apesar de termos consciência de que experiências desse tipo se caracterizam como um grão de areia no oceano, tentamos nestes encontros possibilitar uma atmosfera de um mundo melhor, para uma clientela que já ao longo de suas vidas sofreu com os preconceitos da doença mental. Acreditamos que esta experiência por ter possibilitado um enriquecimento à todos, coordenadora e clientes, valeu e está valendo a pena. 


\begin{abstract}
It is an experience report done with chronic psycotic clients, in a process of institution desconstruction, that have been followed by a nurse in a CAPS*/NAPS from Florianópolis, during ten years, it is from 1989 to 1999 . By the end of this period, it can be visualized that chronic psycotic clients, when they are in a sistematic outpatient attendance with a link in a therapeutic group, can keep a reasonable health life, reaching their goals, overcoming their crises and keeping themselves out of the mental hospital. * CAPS: Psychosocial Service Center
\end{abstract}

KEYWORDS: Psychotic clients, nursing, psychiatric assistance, CAPS.

RESUMEN: se trata del relato de experimento realizado con clientes psicóticos crónicos desinstitucionalizados, que fueron acompanădos por una enfermera en un CAPS/NAPS de Florianópolis, durante diez años, de 1989 al 1999. Al final de esse periodo, fue posible verificar que clientes psicóticos crónicos, cuando acompañados sistematicamente con vinculado con un grupo terapéutico, consiguen mantener una vida relativamente saludable, alcanzando objetivos, superando crisis y manteniendose fuera de los muros del manicomio.

PALABRAS CLAVE: clientes psicóticos, enfermeria, assistencia psiquiátrica, CAPS.

\title{
REFERÊNCIAS BIBUOGRÁFICAS
}

BRASIL. Ministério da Saúde. Relatório final da $2^{a}$ Conferência Nacional de Saúde Mental. Brasilia, 1994.

FRAGA, Maria Nazaré de Oliveira. Construçăo da reforma psiquiátrica brasileira - Questōes sobre o modo de inserçăo da enfermagem. Congresso Brasileiro de Enfermagem, 45., 1993, Recife. Anais... ABEn/PE: Ed. Universitária da UFPE, 1994.

LOUZA Neto, Mário Rodrigues. Convivendo com a Esquizofrenia .Săo Paulo: Lemos Editorial, 1995.

ZIMERMAN, Davis E.; OSORIO, Luis Carlos. Como trabalhamos com grupos. Porto Alegre: Artes Médicas, 1977. 